\title{
Standardization of a molecular method for epidemiologic identification of Leishmania strains
}

\author{
R.F. Rocha ${ }^{1 *}$, E.V. Menezes ${ }^{1 *}$, A.R.E.O. Xavier ${ }^{1 *}$, V.A. Royo ${ }^{1}$, \\ D.A. Oliveira ${ }^{1}$, A.F.M. Júnior ${ }^{1}$, E.S. Dias ${ }^{2}$, A.C.V.M.R. Lima ${ }^{2}$ and \\ E.M. Michalsky ${ }^{2}$ \\ ${ }^{1}$ Laboratório de Bioprospecção e Recursos Genéticos, \\ Departamento de Biologia, Centro de Ciências Biológicas e da Saúde, \\ Universidade Estadual de Montes Claros, \\ Campus Universitário Professor Darcy Ribeiro, Montes Claros, MG, Brasil \\ ${ }^{2}$ Centro de Pesquisas René Rachou, Unidade da FIOCRUZ, Belo Horizonte, \\ MG, Brasil \\ *These authors contributed equally to this study. \\ Corresponding author: E.V. Menezes \\ E-mail: menezes.elytania@gmail.com
}

Genet. Mol. Res. 15 (4): gmr.15048854

Received June 6, 2016

Accepted July 12, 2016

Published October 6, 2016

DOI http://dx.doi.org/10.4238/gmr.15048854

Copyright $($ C 2016 The Authors. This is an open-access article distributed under the terms of the Creative Commons Attribution ShareAlike (CC BY-SA) 4.0 License.

\begin{abstract}
Molecular studies of the evolutionary relationships among Leishmania species suggest the presence of high genetic variation within this genus, which has a direct effect on public health in many countries. The coexistence of species in a particular region can result in different leishmaniasis clinical forms and treatment responses. We aimed to standardize the kinetoplast DNA (kDNA) enterobacterial repetitive intergenic consensus (ERIC) sequence polymerase chain reaction (PCR) method for molecular epidemiological identification
\end{abstract}


of Leishmania strains, and estimate existing inter-strain genomic differences and kDNA signatures using this technique. ERIC-PCR of genomic DNA revealed genetic polymorphisms between species, although some strains shared many DNA fragments. Leishmania guyanensis, L. amazonensis, and L. braziliensis clustered together in a dendrogram with similarities ranging from 42.0 to $61.0 \%$, whereas L. chagasi grouped with these three species with a similarity of $28.0 \%$. After amplification of kDNA, 780-bp bands were extracted from an agarose gel and purified for analysis of its genetic signature. kDNA ERIC-PCR electrophoretic patterns consisted of 100- to 600bp fragments. Using these profiles, L. braziliensis and L. guyanensis grouped with a similarity of $26.0 \%$, and L. amazonensis and L. chagasi clustered based on a similarity of $100 \%$. The electrophoretic profiles and dendrograms showed that, for epidemiological identification by ERIC-PCR, genomic DNA had greater discriminatory power than kDNA did. More strains need to be analyzed to validate the kDNA ERIC-PCR method. The genomes of these strains should be sequenced for better epidemiological identification of Leishmania species.

Key words: Genetic variability; Kinetoplast; Polymorphism; Genetic similarity

\section{INTRODUCTION}

Leishmaniasis is a group of infectious and parasitic diseases caused by various species of Leishmania protozoa, with a wide spectrum of clinical manifestations involving the skin, mucosa, and internal organs (Alvar et al., 2012). Leishmania is one of several genera within the Trypanosomatidae family, and is characterized in part by the kinetoplast, an organelle composed of DNA (kDNA). This structure accounts for $15-35 \%$ of the total cellular DNA and multiplies independently of the genomic DNA (Simpson et al., 1987). Leishmaniasis is transmitted by the bite of female insects belonging to the Psychodidae family, Phlebotominae subfamily, known as sand flies (Desjeux and Alvar, 2003). Lutzomyia longipalpis is considered the main vector of this disease (Lainson and Rangel, 2005).

Leishmania species are divided into two subgroups, Viannia and Leishmania, and the disease into two types, cutaneous and visceral. Cutaneous leishmaniasis is principally caused by Leishmania (Viannia) braziliensis, Leishmania (Viannia) guyanensis, and Leishmania (Leishmania) amazonensis, and more rarely by Leishmania (Viannia) lainsoni, Leishmania (Viannia) naiff, Leishmania (Viannia) shawi, and Leishmania (Viannia) lindenbergi, whereas Leishmania (Leishmania) chagasi is the causative agent of visceral leishmaniasis (Lessa et al., 2007; Ministério da Saúde, 2007; Lainson, 2010).

L. guyanensis, L. amazonensis, and L. braziliensis have been found simultaneously in the Americas, Mediterranean Basin, Middle East, and Central Asia, mainly in Afghanistan, Algeria, Colombia, the Islamic Republic of Iran, and the Syrian Arab Republic. L. chagasi is found in the Indian subcontinent and East Africa, particularly Bangladesh, Brazil, Ethiopia, India, and Sudan (WHO, 2015).

Leishmaniasis is endemic in 85 countries on five continents, with a total of 310 million

Genetics and Molecular Research 15 (4): gmr.15048854 
people at risk. An estimated 1.3 million new cases of this disease occur annually worldwide (WHO, 2015). The Leishmania genus includes a large number of described species. Studies having used molecular methods to analyze the evolutionary relationships between these organisms suggest that the genus is highly variable (Boité et al., 2012; Kuhls et al., 2013). This variation directly affects public health in numerous countries, particularly Brazil, where many species coexist in particular regions and cause different clinical forms of leishmaniasis with distinct treatment responses, making diagnosis based on geographical location highly challenging (Grimaldi and Tesh, 1993; Cupolillo et al., 2003).

Molecular methods have been used previously for the identification and characterization of the causative agents of leishmaniasis, mainly in studies of genetic variability. Due to the specificity of these techniques, detection and genetic characterization of the disease can be performed simultaneously (Hulton et al., 1991; Harris et al., 1996).

The methods used include enterobacterial repetitive intergenic consensus (ERIC) sequence-based polymerase chain reaction (PCR). ERIC-PCR enables the characterization, comparison, and identification of variations in the genomes of homologous bacterial strains, and facilitates epidemiological research (Versalovic et al., 1991; Dorneles et al., 2014; Carvalho et al., 2016). Furthermore, it has high discriminatory power for differentiating closely related species and shows good reproducibility compared to other methods (Fendri et al., 2013; Carvalho et al., 2016).

Thus, the goal of this study was to standardize the ERIC-PCR approach for the epidemiological identification of Leishmania strains using genomic DNA and kDNA. We estimated the genomic differences between four Leishmania species and established their kDNA signatures. This is the first study to employ nested PCR with ERIC-PCR of the kinetoplast region.

\section{MATERIAL AND METHODS}

\section{Leishmania DNA}

We used genomic DNA isolated from pure cultures of four Leishmania species (L. braziliensis, L. chagasi, L. guyanensis, and L. amazonensis) for characterization. DNA samples $(100 \mathrm{ng} / \mu \mathrm{L})$ were provided by the René Rachou Research Center (Centro de Pesquisas René Rachou), a FIOCRUZ branch in Belo Horizonte, State of Minas Gerais, Brazil. Each DNA sample used was quantified by 1.0-1.5\% agarose gel electrophoresis and employed in PCR and ERIC-PCR.

\section{ERIC-PCR}

Characterization of the genetic profiles of and clonal relationships between isolates of L. braziliensis, L. chagasi, L. guyanensis, and L. amazonensis was performed by genomic DNA polymorphism analysis. We used previously described PCR primers targeting conserved regions of the ERIC sequence, as follows: ERIC 1, 5'-TGT AAG CTC CTG GGG ATT AAC3'; and ERIC 2, 5'-AAG TAA GTG ACT GGG GTG AGC G-3' (Duan et al., 2009). Reactions were performed in a 50- $\mu \mathrm{L}$ mix containing $1 \mathrm{X}$ Taq buffer from a KAPA PCR kit (KAPA Biosystems, Wilmington, MA, USA), $2.5 \mathrm{mM} \mathrm{MgCl}_{2}, 1 \mu \mathrm{M}$ deoxynucleotides, $0.5 \mathrm{U}$ Kappa Taq polymerase (KAPA Biosystems, Wilmington, MA, USA), $1 \mu \mathrm{M}$ each primer, and $10 \mu \mathrm{L}$ Leishmania DNA. Amplification conditions were as follows: one initial cycle of denaturation at

Genetics and Molecular Research 15 (4): gmr.15048854 
$95^{\circ} \mathrm{C}$ for $1 \mathrm{~min}$, followed by 40 cycles of denaturation at $94^{\circ} \mathrm{C}$ for $1 \mathrm{~min}$, annealing at $52^{\circ} \mathrm{C}$ for $1 \mathrm{~min}$, and extension at $72^{\circ} \mathrm{C}$ for $2 \mathrm{~min}$, before a final extension at $72^{\circ} \mathrm{C}$ for $7 \mathrm{~min}$. Amplicons were visualized on a $1.5 \%$ agarose gel stained with ethidium bromide and photodocumented using the Gel Logic 212 Pro system (CARESTREAM, New Haven, CT, USA).

Amplification profiles were visually analyzed by four observers and converted into a binary data matrix according to the presence or absence of DNA fragments. To assess the genetic relationships between isolates, the matrix was subjected to multivariate cluster analysis by the complete linkage method to calculate Euclidean distances and generate a dendrogram using the statistical program Minitab version 16 (Minitab Inc., State College, PA, USA). The Escherichia coli BL21(DE3+) strain was used as an outgroup.

\section{kDNA PCR}

We used the kDNA F (5'-CCA GTT TCC CGC CCC G-3') and kDNA R (5'-GGG GTT GGT GGT GTA AAA TAG-3') primers to amplify a 780-bp sequence in a conserved region of Leishmania minicircle kDNA (kinetoplast mitochondrial DNA) by PCR. The reactions were performed in a $25-\mu \mathrm{L}$ mix containing $10 \mathrm{X}$ buffer, $2 \mathrm{mM} \mathrm{MgCl}, 1 \mu \mathrm{M}$ deoxynucleotides, $1 \mathrm{U}$ Taq polymerase, $1.0 \mu \mathrm{M}$ each primer, and $5 \mu \mathrm{L}$ Leishmania DNA. Cycling conditions were as follows: an initial denaturation at $94^{\circ} \mathrm{C}$ for $5 \mathrm{~min}$, followed by 35 cycles of denaturation at $94^{\circ} \mathrm{C}$ for $1 \mathrm{~min}$, annealing at $50^{\circ} \mathrm{C}$ for $1 \mathrm{~min}$, and extension at $72^{\circ} \mathrm{C}$ for $1 \mathrm{~min}$, prior to a final extension at $72^{\circ} \mathrm{C}$ for $30 \mathrm{~min}$. PCR products were visualized on a $1 \%$ agarose gel stained with ethidium bromide and photodocumented as above.

\section{kDNA purification (kDNA PCR)}

Following kDNAPCR and visualization of the products by $1 \%$ agarose gel electrophoresis, the 780-bp amplified fragment for each Leishmania strain was extracted from the gel and purified using the Wizard SV Gel and PCR Clean-Up System (Promega, Madison, WI, USA).

\section{Nested PCR (kDNA ERIC-PCR)}

To determine kDNA signatures, the purified 780-bp fragments amplified by kDNA PCR as described above were used in ERIC-PCR. The ERIC 1 and ERIC 2 primers mentioned above, complementary to conserved ERIC sequences, were employed. The $50-\mu \mathrm{L}$ reactions comprised 1X KAPA PCR kit Taq buffer (KAPA Biosystems, Wilmington, MA, USA), 2.5 $\mathrm{mM} \mathrm{MgCl}, 1 \mu \mathrm{M}$ deoxynucleotides, $0.5 \mathrm{U}$ KAPA Taq polymerase (KAPA Biosystems), 1 $\mu \mathrm{M}$ each primer, and $5 \mu \mathrm{L}$ purified Leishmania DNA. The following amplification conditions were used: initial denaturation at $95^{\circ} \mathrm{C}$ for $3 \mathrm{~min}$, followed by 40 cycles of denaturation at $92^{\circ} \mathrm{C}$ for $1 \mathrm{~min}$, annealing at $36^{\circ} \mathrm{C}$ for $1 \mathrm{~min}$, and extension at $72^{\circ} \mathrm{C}$ for $1 \mathrm{~min}$, before a final extension for $16 \mathrm{~min}$. The amplified products were visualized on a $1.5 \%$ agarose gel stained with ethidium bromide and photodocumented as outlined above.

Amplification profiles were visually analyzed by four observers and converted into binary data according to the presence or absence of DNA fragments. Genetic relationships between isolates were estimated by subjecting the resulting matrix to multivariate completelinkage cluster analysis to calculate Euclidean distances and generate a dendrogram in Minitab version 16, as for the genomic DNA ERIC-PCR.

Genetics and Molecular Research 15 (4): gmr.15048854 


\section{RESULTS}

In the present study, molecular characterization of four Leishmania strains isolated from pure cultures was performed to determine genomic differences and similarities and kDNA signatures.

ERIC-PCR electrophoretic profiles were generated by amplifying genomic DNA from the four Leishmania species using the ERIC 1 and ERIC 2 primers. Polymorphic DNA banding patterns of good intensity were observed, revealing a degree of genetic variation. DNA fragments ranged in size from 100 to $2000 \mathrm{bp}$, and although high genetic variance was observed, some profiles obtained from different strains shared certain bands in common (Figure 1).

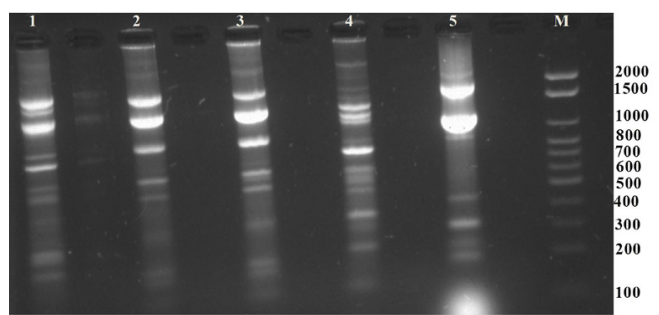

Figure 1. Enterobacterial repetitive intergenic consensus sequence-based polymerase chain reaction to compare the genetic profiles of different Leishmania species standard strains. Lane $1=$ Leishmania braziliensis; lane $2=$ Leishmania guyanensis; lane $3=$ Leishmania amazonenses; lane $4=$ Leishmania chagasi; lane $5=$ Escherichia coli BL21(DE3+) (outgroup). Lane $M=100$-bp DNA molecular weight marker (Norgen Biotek, Thorold, Canada); lengths (bp) are indicated to the right of the $1.5 \%$ agarose gel.

By examining the distinct fragments generated, we constructed a binary matrix from the electrophoretic profiles based on the presence or absence of DNA bands, which were analyzed in sets and used to construct a dendrogram. Similarity analysis allowed classification of the Leishmania strains into a single cluster (I). Within this, L. guyanensis and L. amazonensis (IA 2.1 and IA 2.2) formed a group with a similarity of $61.0 \%$, with which L. braziliensis clustered with $42.0 \%$ similarity (IA1 and IA2). L. chagasi was associated with the group comprising these three species based on a similarity of $28.0 \%$ (IA and IB). E. coli BL21(DE3+) (group II) was used as an outgroup in the analysis; as expected, no genetic similarity with the Leishmania strains in group I was observed (Figure 2).

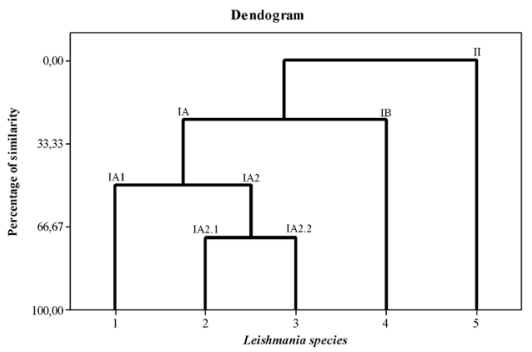

Figure 2. Dendrogram of the genetic relationships between Leishmania species standard strains obtained by enterobacterial repetitive intergenic consensus sequence-based polymerase chain reaction. Leishmania strains were clustered together into group I, with Escherichia coli BL21(DE3+) forming group II, according to percentage similarity. 1 =Leishmania braziliensis. 2 =Leishmania guyanensis. $3=$ Leishmania amazonensis. $4=$ Leishmania chagasi. 5 = Escherichia coli BL21(DE3+) (outgroup).

Genetics and Molecular Research 15 (4): gmr.15048854 
To characterize kDNA profiles, PCR was carried out using kDNA F and kDNA R primers. Satisfactory amplification was observed, almost all the products of which corresponded to kDNA, and the bands were suitable for extraction and purification (Figure 3).

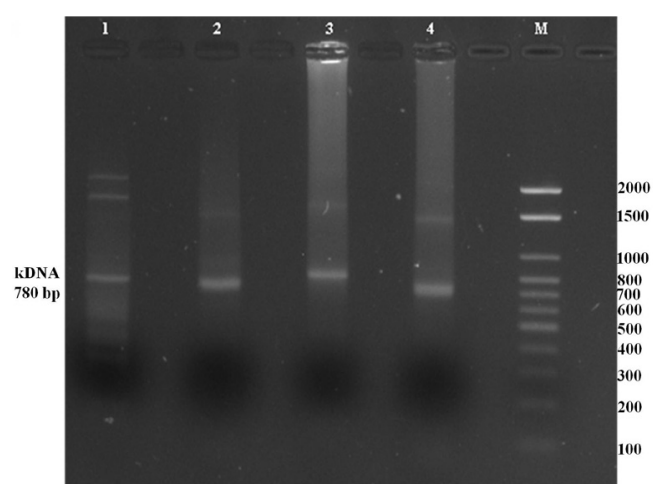

Figure 3. Kinetoplast DNA (kDNA) polymerase chain reaction to analyze kDNA profiles. Lane $1=$ Leishmania braziliensis; lane 2 = Leishmania guyanensis; lane $3=$ Leishmania amazonenses; lane $4=$ Leishmania chagasi . Lane $M=100-b p$ DNA molecular weight marker (Norgen Biotek); lengths (bp) are indicated to the right of the $1 \%$ agarose gel.

The kDNA signatures consisted of a pattern of fragments ranging from 100 to $600 \mathrm{bp}$. A comparison of the size (in bp) and number of the major bands in each kDNA profile revealed similarities and differences between the Leishmania strains (Figure 4).

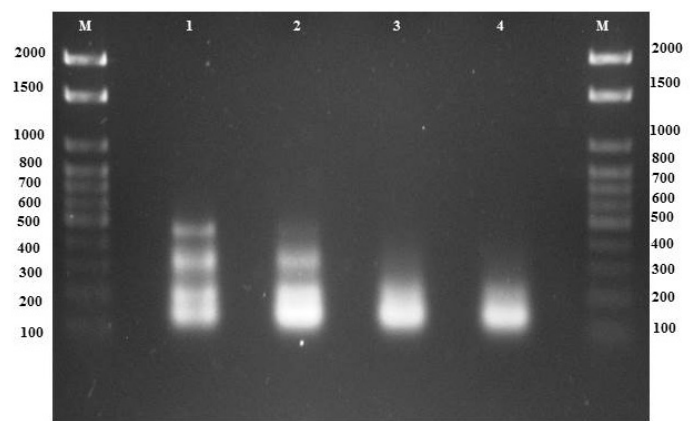

Figure 4. Kinetoplast DNA enterobacterial repetitive intergenic consensus sequence-based polymerase chain reaction to compare the genetic profiles of different Leishmania species standard strains. Lane $M=100$-bp DNA molecular weight marker (Norgen Biotek); lengths (bp) are indicated to the left and right of the $1.5 \%$ agarose gel. Lane 1 = Leishmania braziliensis; lane $2=$ Leishmania guyanensis; lane $3=$ Leishmania chagasi; lane $4=$ Leishmania amazonensis.

The main bands in the kDNA signatures of the different Leishmania species were analyzed and converted into a binary data matrix according to their presence or absence (Figure 4), to construct a dendrogram. The Leishmania strains were categorized into two groups (I and II). Group I consisted of L. braziliensis and L. guyanensis, with $26.0 \%$ similarity (IA and IB), and group II of L. amazonensis and L. chagasi, which exhibited $100 \%$ similarity (IIA and IIB; Figure 5). 


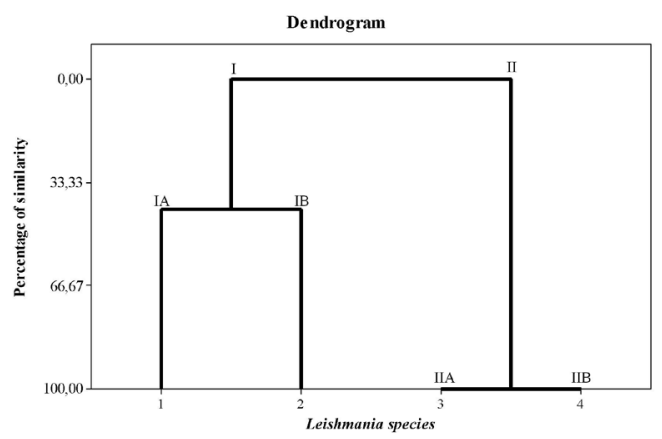

Figure 5. Dendrogram of the genetic relationships between Leishmania species standard strains obtained by kinetoplast DNA enterobacterial repetitive intergenic consensus sequence-based polymerase chain reaction. Leishmania strains were distributed into two groups (I and II) according to percentage similarity. $1=$ Leishmania braziliensis. 2 =Leishmania guyanensis. 3 =Leishmania amazonensis. $4=$ Leishmania chagasi.

\section{DISCUSSION}

Molecular methods have been used previously to identify and characterize the causative agents of leishmaniasis, mainly in studies of genetic variability. Given the specificity of such techniques, the detection and genetic characterization of this disease can be achieved simultaneously (Hulton et al., 1991; Harris et al., 1996; da Silva et al., 2004).

Madruga et al. (2002) demonstrated the use of ERIC-PCR in the characterization of a protozoan parasite. The authors conducted a molecular epidemiological study to identify the genetic diversity present among Babesia bigemina protozoa isolated from five states in Brazil. Genetic analysis was performed by random amplification of polymorphic DNA (RAPD), repetitive extragenic palindromic elements (REP)-PCR, and ERIC-PCR, which revealed polymorphisms among the isolates. The RAPD results were reproducible, in that the amplified polymorphic fragments were consistently detected, with the exception of certain weaker bands that were not always generated in reactions using different DNA preparations. The study also demonstrated that both REP- and ERIC-PCR can be used for genetic analysis of protozoan parasites, although the latter has greater discriminatory power than the former.

The goal of the present study was to standardize the ERIC-PCR method for epidemiological identification of Leishmania strains using genomic DNA and kDNA. We estimated the genomic differences between various Leishmania species and determined their kDNA signatures. This is the first study to use nested PCR with ERIC-PCR of the kinetoplast region.

The pattern of polymorphic DNA fragments resulting from ERIC-PCR revealed some degree of genetic variation between the Leishmania strains (Figure 1). The profiles observed were similar to those recorded in the literature for different Leishmania species, demonstrating the genetic variability of these organisms. The ERIC-PCR products described by Leal (2010) ranged in size from 100 to $1700 \mathrm{bp}$ for Leishmania reference samples (FIOCRUZ) and isolates from 11 patients with visceral leishmaniasis. Yazidi et al. (2015) used RAPD-PCR to determine the genetic variability of 39 Leishmania major isolates from five endemic foci. Their analysis revealed a high degree of polymorphism (43\%) among isolates, and showed that $99 \%$ of the observed variation was within, rather than between, each region studied.

Although in the present study, fragment sizes ranging from 100 to $2000 \mathrm{bp}$ were generated, some strains shared certain DNA bands (Figure 1), as reflected in the dendrogram,

Genetics and Molecular Research 15 (4): gmr.15048854 
in which species were grouped by similarity (Figure 2).

Species in the Leishmania genus are morphologically similar, with slight differences. Current molecular techniques enable the evaluation of the intrinsic characteristics of these parasites. The development of these methods has resulted in important advances in our knowledge of Leishmania genotypes and the possibility of characterizing them on an individual level (Cupolillo et al., 1998; Schriefer et al., 2004).

L. guyanensis, L. amazonensis, and L. braziliensis were grouped in our dendrogram with high similarity values, ranging from 61.0 to $42.0 \%$ (Figure 2 ). This can be explained by the results of previous studies, in which these species have all been identified as belonging to the Viannia subgroup and causing cutaneous leishmaniasis (Cupolillo et al., 1998; Schriefer et al., 2004). The differences and similarities found also reveal a possible association between Leishmania genetic profiles and the reservoir type and geographical origin of the corresponding species. According to Gomes et al. (1995), the diversity of Leishmania species in the Viannia subgroup is less pronounced among populations found in nearby regions. Genotypic polymorphisms correlate with the geographic origin of isolates for Old World (Schönian et al., 2000; Toledo et al., 2002) and New World Leishmania species (Gomes et al., 1995; Cupolillo et al., 2003).

L. guyanensis is predominantly present in the states of Amazonas and Acre. (Gontijo and de Carvalho, 2003; Silveira et al., 2004). L. amazonensis can be found in various regions of Brazil (Barral et al., 1993), as can L. braziliensis, although at a low frequency in Amazonas (Bittencourt and Barral, 1991; Gontijo and de Carvalho, 2003; Carvalho et al., 2015).

L. chagasi exhibited the lowest similarity to the other three species $(28.0 \%)$ in the genomic DNA dendrogram, perhaps as it belongs to the Leishmania subgroup and causes visceral leishmaniasis. Despite these differences in subgenus and the type of leishmaniasis caused, estimation of genetic distance revealed some similarity when the species were grouped together (group I). Moreover, they belong to the same genus and may occur concurrently in the same geographic regions (Lessa et al., 2007; Ministério da Saúde, 2007; Lainson, 2010). E. coli BL21(DE3+) (group II) was used as an outgroup. As expected, this isolate showed no genetic similarity to the Leishmania strains in group I (Figure 2).

Previous studies have indicated that genetic variations between Leishmania isolates correlate with clinical manifestations of the disease and its response to anti-leishmanial treatments. Oryan et al. (2013) conducted kDNA sequencing to identify heterogeneity among isolates of L. major, which causes cutaneous leishmaniasis, and its relationship with clinical features of this disease in humans. Nested PCR revealed a high degree of polymorphism, whereas sequencing analysis suggested associations between the genetic heterogeneity of the parasite, its geographical origin, and clinical manifestations of leishmaniasis in humans. Patients with the same clinical characteristics and geographical origin were infected with phylogenetically neighboring strains.

van Thiel et al. (2011) observed differences between the clinical conditions and therapeutic responses of Dutch military personnel infected with L. major from southern and northern Afghanistan. The clinical presentation of cutaneous leishmaniasis was milder in the south, and study subjects infected in this region of the country appeared to respond better to leishmanicidal treatment. Molecular analysis of the isolates indicated that these differences may have had a genetic basis. The severity of leishmaniasis is influenced by the pathogenicity of the parasite species or strain and the host immune response (Garcia et al., 2005). These findings may also explain why the similarity-based groupings in the present study correlated with clinical manifestations.

Genetics and Molecular Research 15 (4): gmr.15048854 
Cutaneous leishmaniasis exhibits several clinical forms. The localized cutaneous form is characterized by primary involvement of the skin. Single or multiple (up to 200) ulcerative lesions commonly result. All Leishmania species related to cutaneous involvement can cause this form, although their prevalence varies between geographic regions (Ministério da Saúde, 2009).

The disseminated cutaneous form is relatively rare, being observed in up to $2 \%$ of cases. It is characterized by the appearance of multiple acneiform papular lesions on various body parts, particularly the face and torso. The species recognized as causative agents include $L$. amazonensis and L. braziliensis (Barral et al., 1993; Barral et al., 1995; Gontijo and de Carvalho, 2003). The recidiva cutis form is marked by nodular lesions of late onset and long duration. Initially appearing in isolated instances, they then become confluent around or within the scar of previous Leishmania injuries. In Brazil, this form is caused by L. amazonensis and L. braziliensis (Bittencourt and Barral, 1991; Barral et al., 1993; Gontijo and de Carvalho, 2003).

The diffuse cutaneous form, an unusual type with aggressive clinical manifestations, is present in Brazil and caused by L. amazonensis. It first presents as a single lesion, evolving slowly into several non-ulcerated nodules and plaques covering large areas of the skin (Barral et al., 1993). Mucosal leishmaniasis is a latent, chronic form resulting in metastatic lesions of mucous membranes. It is principally caused by L. braziliensis, but other species such as $L$. amazonensis and L. guyanensis have also been implicated (Barral et al., 1993; Gontijo and de Carvalho, 2003; Silveira et al., 2004).

Therefore, the variety and extent of the clinical manifestations characteristic of Leishmania infection, and in particular, variations in pathogenicity, may derive from the genetic diversity of both host and parasite.

In this study, following extraction and purification of the 780-bp kDNA fragments, ERIC-PCR analysis was carried out. The electrophoretic pattern comprised bands ranging from 100 to $600 \mathrm{bp}$ (Figure 4), and considerably fewer DNA fragments were generated compared to ERIC-PCR of genomic DNA (Figure 1). Our results are consistent with those of previous studies, as the kinetoplast corresponds to $15-35 \%$ of the total cellular DNA and multiplies independently of the genomic DNA. kDNA is made up of thousands of minicircles forming a complex network with maxicircles of circular and compact DNA molecules (Simpson et al., 1987). Considering the detection of distinct bands in the electrophoretic profiles, the binary matrix of present and absent DNA fragments changed significantly because of the reduction in polymorphic bands resulting from kDNA amplification.

We compared the size (in bp) and number of the principal DNA fragments of each kDNA signature generated by ERIC-PCR. It was possible to depict the relative similarities and differences between the patterns obtained from each Leishmania strain using a dendrogram (Figure 5).

The genetic distance observed between L. braziliensis and L. guyanensis was larger in the ERIC-PCR-based dendrogram created using kDNA than in that obtained with genomic DNA, which grouped them with a similarity of $42.0 \%$ (IA1 and IA2). After kDNA ERICPCR and construction of a new dendrogram, the above species were included in group I with $26.0 \%$ similarity (IA and IB). However, L. amazonensis and L. chagasi demonstrated $100 \%$ similarity (IIA and IIB), and were clustered in a second group (Figure 5), owing to the decreased number of polymorphic DNA fragments. However, the $100 \%$ similarity observed between L. amazonensis and L. chagasi was unexpected, as the former belongs to the Viannia subspecies and causes cutaneous leishmaniasis, whereas the latter is a member of the Leishmania subgroup and causes the visceral form. This result may be due to the small number of DNA bands in the electrophoretic profiles kDNA ERIC-PCR, since the amplified

Genetics and Molecular Research 15 (4): gmr.15048854 
fragment kDNA is too small to generate a higher band profile. Comparing the ERIC-PCR electrophoretic profiles and dendrograms, those based on genomic DNA gave better results than those generated using the kinetoplast region. Genomic DNA amplified by ERIC-PCR yielded products that ranged in size from 100 to $2000 \mathrm{bp}$, whereas kDNA signatures consisted of 100- to 600-bp fragments. The kDNA ERIC-PCR involved multiple amplification reactions of kinetoplast sequences only. Thus, few binding regions were available for the ERIC primers to initiate DNA amplification, explaining the limited variation of the bands generated by nested PCR (Simpson et al., 1987). Therefore, the dendrogram obtained from these nested PCR profiles contained different groupings from that based on ERIC-PCR of genomic DNA, with decreased genetic distance between strains because of the few DNA fragments analyzed. A greater number of fragments results in improved discriminatory power. In keeping with the present study, Alvarenga et al. (2012) demonstrated a certain degree of polymorphism among kinetoplast genetic signatures. Low-stringency single specific primer (LSSP)-PCR of kDNA hypervariable regions previously amplified from Leishmania infantum isolated from humans revealed genetic signatures consisting of 93- to 619-bp DNA fragments and high intraspecific variation. The heterogeneity among $L$. infantum kinetoplast profiles obtained by LSSP-PCR may reflect not only the high genetic diversity frequently observed in Leishmania strains, but also the substantial intraspecific variation between kDNA molecules within the Trypanosomatidae family.

\section{CONCLUSION}

Our results show that for epidemiological identification of Leishmania strains, the ERIC-PCR method is more effective when genomic DNA, rather than kDNA, is used. Epidemiological studies could be conducted to more precisely determine which strains are present in specific regions, to obtain an accurate assessment of the leishmaniasis types affecting different populations, and the appropriate treatments.

The polymorphic DNA patterns resulting from ERIC-PCR revealed a degree of genetic variation between the Leishmania strains. Based on this information, we hypothesized which differences were caused by mutations; however, DNA sequencing is required to verify these predictions. The kDNA ERIC-PCR amplification products resulted in a dendrogram showing a similarity of $100 \%$ between L. amazonensis and L. chagasi. This may have been due to the limitations of the electrophoretic profiles generated by this technique, or because only four strains were used. Thus, it is necessary to include additional strains to validate the ERIC-PCR method for genomic DNA and determine their genome sequences to enable the epidemiological identification of Leishmania species.

\section{Conflicts of interest}

The authors declare no conflict of interest.

\section{ACKNOWLEDGMENTS}

We thank the René Rachou Research Center (Centro de Pesquisas René Rachou), a FIOCRUZ branch in Belo Horizonte, Minas Gerais, for the DNA isolated from pure Leishmania

cultures. We thank the Laboratory of Bioprospecting and Genetic Resources (Laboratório

Genetics and Molecular Research 15 (4): gmr.15048854 
de Bioprospecção e Recursos Genéticos) and the Graduate Program in Biotechnology of UNIMONTES for the opportunity and Fundação de Amparo à Pesquisa do Estado de Minas Gerais (FAPEMIG) for the encouragement and financial support.

\section{REFERENCES}

Alvar J, Vélez ID, Bern C, Herrero M, et al.; WHO Leishmaniasis Control Team (2012). Leishmaniasis worldwide and global estimates of its incidence. PLoS One 7: e35671.http://dx.doi.org/10.1371/journal.pone.0035671

Alvarenga JS, Ligeiro CM, Gontijo CM, Cortes S, et al. (2012). KDNA genetic signatures obtained by LSSP-PCR analysis of Leishmania (Leishmania) infantum isolated from the new and the old world. PLoS One 7: e43363. http://dx.doi. org/10.1371/journal.pone.0043363

Barral A, Barral-Netto M, Yong EC, Brownell CE, et al. (1993). Transforming growth factor beta as a virulence mechanism for Leishmania braziliensis. Proc. Natl. Acad. Sci. USA 90: 3442-3446. http://dx.doi.org/10.1073/pnas.90.8.3442

Barral A, Costa JM, Bittencourt AL, Barral-Netto M, et al. (1995). Polar and subpolar diffuse cutaneous leishmaniasis in Brazil: clinical and immunopathologic aspects. Int. J. Dermatol. 34: 474-479.

Bittencourt AL and Barral A (1991). Evaluation of the histopathological classifications of American cutaneous and mucocutaneous leishmaniasis. Mem. Inst. Oswaldo Cruz 86: 51-56. http://dx.doi.org/10.1590/S0074$\underline{02761991000100009}$

Boité MC, Mauricio IL, Miles MA and Cupolillo E (2012). New insights on taxonomy, phylogeny and population genetics of Leishmania (Viannia) parasites based on multilocus sequence analysis. PLoS Negl. Trop. Dis. 6: e1888. http:// dx.doi.org/10.1371/journal.pntd.0001888

Carvalho FS, Wenceslau AA, Albuquerque GR, Munhoz AD, et al. (2015). Leishmania (Viannia) braziliensis in dogs in Brazil: epidemiology, co-infection, and clinical aspects. Genet. Mol. Res. 14: 12062-12073. http://dx.doi. org/10.4238/2015.October.5.19

Carvalho AA, Cardoso LLS, Nogueira HS, Menezes VE, et al. (2016). Characterization and molecular epidemiology of extensively prevalent, nosocomial, isolates of the drug-resistant Acinetobacter spp. Genet. Mol. Res. 15: 2016 http:// dx.doi.org/10.4238/gmr. 15038608 .

Cupolillo E, Momen H and Grimaldi Jr G (1998). Genetic diversity in natural populations of New World Leishmania. Mem. Inst. Oswaldo Cruz 93: 663-668. http://dx.doi.org/10.1590/S0074-02761998000500018

Cupolillo E, Brahim LR, Toaldo CB, de Oliveira-Neto MP, et al. (2003). Genetic polymorphism and molecular epidemiology of Leishmania (Viannia) braziliensis from different hosts and geographic areas in Brazil. J. Clin. Microbiol. 41: 3126-3132. http://dx.doi.org/10.1128/JCM.41.7.3126-3132.2003

da Silva ES, Gontijo CM, Pacheco RdaS and Brazil RP (2004). Diagnosis of human visceral leishmaniasis by PCR using blood samples spotted on filter paper. Genet. Mol. Res. 3: 251-257.

Desjeux P and Alvar J (2003). Leishmania/HIV co-infections: epidemiology in Europe. Ann. Trop. Med. Parasitol. 97 (Suppl 1): 3-15.http://dx.doi.org/10.1179/000349803225002499

Dorneles EM, Santana JA, Ribeiro D, Dorella FA, et al. (2014). Evaluation of ERIC-PCR as genotyping method for Corynebacterium pseudotuberculosis isolates. PLoS One 9: e98758.http://dx.doi.org/10.1371/journal.pone.0098758

Duan H, Chai T, Liu J, Zhang X, et al. (2009). Source identification of airborne Escherichia coli of swine house surroundings using ERIC-PCR and REP-PCR. Environ. Res. 109: 511-517. http://dx.doi.org/10.1016/j.envres.2009.02.014

Fendri I, Ben Hassena A, Grosset N, Barkallah M, et al. (2013). Genetic diversity of food-isolated Salmonella strains through pulsed field gel electrophoresis (PFGE) and enterobacterial repetitive intergenic consensus (ERIC-PCR). PLoS One 8: e81315.http://dx.doi.org/10.1371/journal.pone.0081315

Garcia FCB, Santos SSR, Chociay MF, Medeiros ACR, et al. (2005). Métodos subsidiários para o diagnóstico da Leishmaniose Tegumentar Americana (LTA): comparação dos resultados do seqüenciamento de DNA e da PCRRFLP para determinação da espécie de Leishmania em amostras cutâneo-mucosas. An. Bras. Dermatol. 80 (Suppl 3): S339-S344. http://dx.doi.org/10.1590/S0365-05962005001000013

Grimaldi Jr G and Tesh RB (1993). Leishmaniases of the New World: current concepts and implications for future research. Clin. Microbiol. Rev. 6: 230-250. http://dx.doi.org/10.1128/CMR.6.3.230

Gomes RF, Macedo AM, Pena SD and Melo MN (1995). Leishmania (Viannia) braziliensis: genetic relationships between strains isolated from different areas of Brazil as revealed by DNA fingerprinting and RAPD. Exp. Parasitol. 80: 681687.http://dx.doi.org/10.1006/expr.1995.1084

Gontijo B and de Carvalho MdeL (2003). American cutaneous leishmaniasis. Rev. Soc. Bras. Med. Trop. 36: 71-80.

Harris E, Belli A and Agabian N (1996). Appropriate transfer of molecular technology to Latin America for public health and biomedical sciences. Biochem. Educ. 24: 3-12. http://dx.doi.org/10.1016/0307-4412(95)00154-9

Genetics and Molecular Research 15 (4): gmr.15048854 
Hulton CSJ, Higgins CF and Sharp PM (1991). ERIC sequences: a novel family of repetitive elements in the genomes of Escherichia coli, Salmonella typhimurium and other enterobacteria. Mol. Microbiol. 5: 825-834. http://dx.doi. org/10.1111/j.1365-2958.1991.tb00755.x

Kuhls K, Cupolillo E, Silva SO, Schweynoch C, et al. (2013). Population structure and evidence for both clonality and recombination among Brazilian strains of the subgenus Leishmania (Viannia). PLoS Negl. Trop. Dis. 7: e2490. http:// dx.doi.org/10.1371/journal.pntd.0002490

Lainson R (2010). The Neotropical Leishmania species: a brief historical review of their discovery, ecology and taxonomy. Rev. Pan-Amaz. Saúde 1: 13-32.

Lainson R and Rangel EF (2005). Lutzomyia longipalpis and the eco-epidemiology of American visceral leishmaniasis, with particular reference to Brazil: a review. Mem. Inst. Oswaldo Cruz 100: 811-827. http://dx.doi.org/10.1590/ S0074-02762005000800001

Leal CRB (2010). Uso da ERIC-PCR para caracterização de amostras de Leishmania chagasi. Doctoral thesis, Universidade Federal de Mato Grosso do Sul, Campo Grande.

Lessa MM, Lessa HA, Castro TW, Oliveira A, et al. (2007). Mucosal leishmaniasis: epidemiological and clinical aspects. Rev. Bras. Otorrinolaringol. 73: 843-847.http://dx.doi.org/10.1590/S0034-72992007000600016

Madruga CR, Leal CRB, Ferreira AMT, Araújo FR, et al. (2002). Genetic and antigenic analysis of Babesia bigemina isolates from five geographical regions of Brazil. Pesq. Vet. Bras 22: 153-160.

Ministério da Saúde (2007). Manual de vigilância da leishmaniose tegumentar Americana. 2nd edn. Editora do Ministério da Saúde, Ministério da Saúde, Secretaria de Vigilância em Saúde, Brasília.

Ministério da Saúde (2009). Guia de vigilância epidemiológica. 7th edn. Ministério da Saúde, Secretaria de Vigilância em Saúde, Departamento de Vigilância Epidemiológica, Brasília.

Oryan A, Shirian S, Tabandeh MR, Hatam GR, et al. (2013). Genetic diversity of Leishmania major strains isolated from different clinical forms of cutaneous leishmaniasis in southern Iran based on minicircle kDNA. Infect. Genet. Evol. 19: 226-231.http://dx.doi.org/10.1016/j.meegid.2013.07.021

Schönian G, Akuffo H, Lewin S, Maasho K, et al. (2000). Genetic variability within the species Leishmania aethiopica does not correlate with clinical variations of cutaneous leishmaniasis. Mol. Biochem. Parasitol. 106: 239-248. http:// dx.doi.org/10.1016/S0166-6851(99)00216-9

Schriefer A, Schriefer AL, Góes-Neto A, Guimarães LH, et al. (2004). Multiclonal Leishmania braziliensis population structure and its clinical implication in a region of endemicity for American tegumentary leishmaniasis. Infect. Immun. 72: 508-514.http://dx.doi.org/10.1128/IAI.72.1.508-514.2004

Silveira FT, Lainson R and Corbett CE (2004). Clinical and immunopathological spectrum of American cutaneous leishmaniasis with special reference to the disease in Amazonian Brazil: a review. Mem. Inst. Oswaldo Cruz 99: 239251.http://dx.doi.org/10.1590/S0074-02762004000300001

Simpson L, Neckelmann N, de la Cruz VF, Simpson AM, et al. (1987). Comparison of the maxicircle (mitochondrial) genomes of Leishmania tarentolae and Trypanosoma brucei at the level of nucleotide sequence. J. Biol. Chem. 262: 6182-6196.

Toledo A, Martín-Sánchez J, Pesson B, Sanchiz-Marín C, et al. (2002). Genetic variability within the species Leishmania infantum by RAPD. A lack of correlation with zymodeme structure. Mol. Biochem. Parasitol. 119: 257-264. http:// dx.doi.org/10.1016/S0166-6851(01)00424-8

van Thiel PP, van Gool T, Faber WR, Leenstra T, et al. (2011). Variation in clinical presentation and genotype of causative Leishmania major strain in cutaneous leishmaniasis in north and south Afghanistan. Am. J. Trop. Med. Hyg. 85: 6063. http://dx.doi.org/10.4269/ajtmh.2011.10-0531

Versalovic J, Koeuth T and Lupski JR (1991). Distribution of repetitive DNA sequences in eubacteria and application to fingerprinting of bacterial genomes. Nucleic Acids Res. 19: 6823-6831. http://dx.doi.org/10.1093/nar/19.24.6823

WHO (2015). Leishmaniasis fact sheet. Available at [http://www.who.int/mediacentre/factsheets/fs375/en/]. Accessed November 29, 2015.

Yazidi R, Bettaieb J, Ghawar W, Jaouadi K, et al. (2015). RAPD-PCR reveals genetic polymorphism among Leishmania major strains from Tunisian patients. BMC Infect. Dis. 15: 269. http://dx.doi.org/10.1186/s12879-015-1010-0

Genetics and Molecular Research 15 (4): gmr.15048854 